\section{Assessing the Integrated Pest Management Practices of Pennsylvania Nursery Operations}

\author{
James C. Sellmer ${ }^{1}$ \\ Dept. of Horticulture, Penn State University, University Park, PA 16802 \\ Nancy Ostiguy ${ }^{2}$ and Kelli Hoover ${ }^{3}$ \\ Dept. of Entomology, Penn State University, University Park, PA 16802 \\ Kathleen M. Kelley ${ }^{3}$ \\ Dept. of Horticulture, Penn State University, University Park, PA 16802
}

Additional index words. cluster analysis, IPM, segmentation, nursery survey

\begin{abstract}
A mail survey was conducted in 2000 to determine awareness and use of integrated pest management (IPM) practices by nurseries in Pennsylvania. Survey participants were randomly selected from the Pennsylvania Dept. of Agriculture, Bureau of Plant Industry, list of certified nurseries. Participants answered questions pertaining to awareness of common practices, frequency that IPM practices were employed, and specifics on monitoring and pest management decision-making processes. Responses were analyzed by Cluster Analysis (SPSS Inc., Chicago), which resulted in the formation of three distinct segments. The segments were labeled "IPM Savvy" (nursery managers who were more likely to employ IPM practices); "Part-time IPMers" (nursery managers who employed some IPM strategies and were interested in future adoption of IPM practices); and "Reluctant IPMers" (nursery managers who were least likely to employ IPM strategies). The "Part-time IPMers" and "Reluctant IPMers" segments represent a substantial part of the industry $(51 \%)$, who continues to have concerns about the cost, efficacy, and implementation of IPM practices into their businesses. Overall, Pennsylvania growers are aware of IPM practices; however, maintaining permanent records of pests identified and pest management strategies employed remain low. Continued education is warranted to enhance pest monitoring skills and recordkeeping along with demonstrable evidence to the cost effectiveness and marketing benefits that the implementation of IPM practices offer the nursery operators.
\end{abstract}

The ornamental nursery industry has been actively discussing and employing IPM strategies since the mid 1980s (Raupp, 1985; Rhoads, 1985). The impetus for using IPM in nurseries arose for several reasons: 1) public concerns over pesticide use and pesticide residues (Delahaut and Koval, 1994); 2) evidence that employing IPM practices can reduce production expenses by reducing pesticide use and associated labor costs while still providing adequate pest management (Raupp and Cornell, 1988); and 3 ) realization that customers are reluctant to purchase plants that are visibly damaged

Received for publication 5 Nov. 2002. Accepted for publication 8 May 2003. Journal Paper No. 426 of the Pennsylvania State Univ., Dept. of Horticulture. This research was funded in part by an IPM Green Industry Grant from the Pennsylvania Dept. of Agriculture, Bureau of Plant Industry, Harrisburg. We thank Christopher O'Connor, Jason Rosenzweig, Gary Moorman, Greg Hoover, Dave Suchanic, Emelie Swackhamer, Don Narber, Rick Hansen, Sherry Kyne, Lee Bentz, and Edward Rajotte. We extend special thanks to Drs. David J. Beattie and Larry Kuhns for reviewing the manuscript. Use of trade names in this publication does not imply endorsement of products named nor criticism of similar ones not mentioned.

${ }^{1}$ Assistant Professor; to whom reprint requests should be addressed.E-mail: jcs32@psu.edu

${ }^{2}$ Associate Professor.

${ }^{3}$ Assistant Professor.

HortScience, Vol. 39(2), April 2004

HORTSCIENCE, VOL. 39(2), APRIL 2004 educational efforts with commercial nursery producers in Pennsylvania. IPM concepts and practices are disseminated to producers through numerous forums, including organized educational programs, newsletters, websites, volunteer research groups, and industry and regulatory agency publications (J.C. Sellmer, personal observation).

Pennsylvania ranked fourth in the United States in number of farms producing nursery and greenhouse crops in 1997 (Willits and Shields, 2001). The Pennsylvania nursery industry includes nursery growers and nursery stock dealers certified by the Pennsylvania Dept. of Agriculture. Nursery growers were defined as businesses engaged primarily in the propagation and growing of nursery stock. They included garden centers, greenhouse production operations, hobbyists, landscape contractors, landscape nurseries, mail order operations, and production nurseries. In 2000, the Pennsylvania Dept. of Agriculture listed 2,687 certified nurseries on over 39,480 acres and 22,062,195 square feet under glass (Pennsylvania Dept. of Agriculture, 2000). The largest concentration of growers was located in southeastern Pennsylvania, followed by the southwestern and south central regions of the state. In all cases, growers were concentrated around the major metropolitan areas of Philadelphia, Pittsburgh, and Harrisburg.

The most recent nursery pest management surveys conducted nationally and locally occurred in the 1980s, 1990s, and in 2000. A national IPM survey, with an $11.5 \%$ response rate, was conducted in 1993 and focused on IPM practices used by the industry, pest control concerns, pesticide usage, and frequency of application, annual chemical use by number of genera grown, and annual chemical use by nursery size (Higginbotham, 1993). State specific nursery pest management surveys have been reported for Hawaii (Hollingsworth et al., 2000), New York (Lamboy, 2002), Wisconsin (Delahaut and Koval, 1994), and in Pennsylvania in 1979 (Shetlar and Heller, 1984). The Hawaii survey was conducted to determine pesticide use, perception of pest problems, postharvest treatments employed, and to identify research and education areas to develop for tropical pot and cut crops produced and exported to the mainland. The New York survey was directed toward greenhouse growers in order to evaluate the implementation of greenhouse IPM among diverse-sized operations. The Wisconsin survey was conducted in tandem with the initiation of a nursery IPM extension education program. Pennsylvania's survey focused on insecticide and miticide usage among nurseries.

In 2000, a survey of the Pennsylvania nursery industry was conducted to determine the understanding of IPM concepts and practices, and use of these practices. The main objectives of the survey were to determine awareness and use of IPM, and to identify the level of implementation and factors that influence adoption of IPM practices. The overarching goals of this survey were to identify gaps in present educational efforts and develop research and educational programs to expand and support the 
adoption of IPM practices among Pennsylvania nursery growers.

\section{Materials and Methods}

Asurvey was developed in 1999 and mailed to 1800 nurseries randomly selected from the Pennsylvania Dept. of Agriculture, Bureau of Plant Industry 2000 certified nurseries mailing list. Adapted from the Dillman method (Dillman, 2000) a survey was first mailed in Feb. 2000. In Apr. 2000, the same survey recipients received another copy of the survey, followed by a reminder postcard several weeks later.

The 14-page survey consisted of eight sections and 41 questions that focused on general perceptions of IPM principles and implementation of IPM practices; general monitoring activities for insect, disease, and weed pests; control and plant health care practices employed; integrated pest management practices, including perceptions of what limits the use of IPM practices; informational and educational needs, and resources for pest management decision-making; and demographic information. The experiment was approved by the Office for Research Protections, the Pennsylvania State Univ., which oversees the use of human participants.

Data analysis. Cluster analysis (SPSS Inc.) was used to determine whether meaningful IPM practitioner segmentations could be created, based on participant's answers to several questions. Cluster analysis has been used by researchers to define consumer segments related to their preference for horticultural products, such as edible flowers (Kelley et al., 2001), geraniums (Behe et al., 1999), and perceived consumer plant knowledge (Hardy et al., 1999). Variables used for clustering were the nursery stock producers' knowledge and implementation of IPM or cultural practices. Responses were then analyzed to determine the level of knowledge of the participants regarding IPM subject matter. This information will be used by researchers and extension personnel to help them adjust their educational focus on topics where nursery stock producers lack knowledge or implementation. By using K-Means, clusters of sizes 2, 3, and 4 were examined using eight cluster algorithms. After examining each cluster size, the three-cluster solution was selected to develop producerpractitioner segments because it provided the most detail among respondents based on IPM knowledge and implementation.

\section{Results and Discussion}

General. Of the 1800 nurseries receiving surveys, 360 completed them, resulting in a response rate of $20 \%$. This exceeded the past benchmark response rate of $11 \%$ for direct mail surveys (Reed, 1999). Among the respondents, $65 \%$ reported attaining a degree beyond high school. Eighty-seven percent of the respondents were the owners or partners in the nursery, while the remainder were managers and employees (13\%). Nearly all respondents were involved in both the pest management (99\%) and IPM (91\%) decisions at the nursery.
A majority (80\%) of respondents reported gross sales for 1998 of less than $\$ 250,001$. The respondents were evenly divided, with $51 \%$ reporting total production under 3.5 acres and $49 \%$ with greater than 3 acres. Regarding business activities, a majority $(73 \%)$ reported being involved in a combination of nursery-related operations including nursery production, Christmas tree growing, landscape operations, and garden center sales, whereas $18 \%$ reported being strictly involved in production nursery activities. Fifty percent of the nurseries had been in business more than 11 years. More than half of the businesses reported employing more than two full-time, part-time, and seasonal employees.

The top 10 most frequently recognized IPM practices among respondents were monitoring $(86 \%)$; selecting resistant plant varieties $(80 \%)$; keeping records $(80 \%)$; removing heavily infested nursery stock (79\%); removing plant debris (79\%); using the least toxic alternative (77\%); using insecticidal soaps, horticultural oils, or repellents (74\%); isolating plants with pest problems $(74 \%)$; using conventional pesticides (69\%); and maintaining weed-free perimeters $(67 \%)$. To further determine the frequency with which IPM practices are employed, respondents were asked to rate their use of IPM practices on a scale from never to routinely. A majority of the respondents $(63 \%)$ reported routinely employing IPM strategies. Similar levels of awareness and implementation were reported in the 1993 national IPM survey (Higginbotham, 1993), where $86 \%$ of the nurseries were fully $(18 \%)$ or partially (68\%) employing IPM, suggesting that recognition and use of IPM practices remains high among nurseries in Pennsylvania.

Monitoring pests is a cornerstone concept of IPM. Ninety-nine percent of survey respondents reported monitoring for insects at least on a monthly basis with $88 \%$ monitoring for diseases during the same period. Weeds were the least monitored with only $68 \%$ monitoring at least monthly. Although daily scouting may be labor intensive and costly to maintain, weekly or monthly monitoring of pest activities during the growing season may be attainable and fulfills recommendations for monitoring frequency in the mid-Atlantic region (Raupp and Cornell, 1988).

Another important facet of monitoring for pests is keeping permanent records of the pests identified and control practices employed over time. This allows IPM practioners to identify pest trends and persistent pest problems, reduces diagnosis time in future years, and provides documentation of effective and ineffective pest management strategies when the pest reappears in the nursery. Unfortunately, only $25 \%$ of the respondents reported keeping permanent records of pests identified in the nursery. Overall, these results suggest that the respondents are aware of IPM practices; however, they are not equally employing all of the practices at their nursery.

Cluster analysis (SPSS Inc.) was used to determine whether meaningful IPM practitioner segments could be created, based on participant's answers to several key questions regarding implementation of IPM practices, pest monitoring, and identification. Three distinct segments were identified "IPMSavvy," "Part-time IPMer," and "Reluctant IPMer" (Table 1). Each segment clearly defined what practices are currently used to monitor for insects/mites, diseases, and weeds, level of future interest, opinions about IPM, and perceived limitations of IPM practices.

Segment 1. Of the three segments, the largest group, labeled "IPM Savvy," consisted of 176 participants or $49 \%$ of the respondents. These participants routinely implemented IPM strategies (86\%); monitored for weeds once a week during the season (38\%); and were more likely to always identify diseases (42\%), insects or mites (70\%), and weeds (55\%) accurately, compared to the other two segments.

The "IPM Savvy" group was more likely to identify the presence of beneficial insects, mites, and other organisms $(42 \%)$ and consider the incidence of insects or mite pests and number of plants affected (89\%) before deciding to treat for insect or mite problems. When monitoring for plant diseases, this group was more likely to identify the specific disease $(85 \%)$, relate the problem to current and forecasted environmental conditions (53\%), determine disease severity (85\%), and consider plant condition $(78 \%)$ than the other two segments. Similarly, this segment was more likely to target persistent problem weeds $(85 \%)$, target weed control based on a vulnerable point within the life cycle (48\%), and evaluate weed source (48\%).

Because this group's responses were more proactive when answering questions about monitoring for pests $(95 \%)$, they were also more likely to employ techniques that would assist in the practice of IPM. The "IPM Savvy" group tended to select pesticides $(66 \%)$ and use cultural practices $(68 \%)$ that conserve beneficial insects as well as cultural practices that reduce weeds $(82 \%)$. In addition, this segment used insecticidal soaps (37\%), horticultural oils (42\%), and natural products such as botanicals (29\%) more often than the other two population segments.

Current monitoring practices also assisted the "IPM Savvy" group when deciding when to spray for insects/mites or disease organisms. Of this segment, $0 \%$ always sprayed, $2 \%$ often sprayed, and $20 \%$ and $23 \%$ sometimes sprayed for insects/mites or diseases, respectively, on a calendar schedule. A much larger percentage, $78 \%$ and $75 \%$, respectively, rarely sprayed for insects/mites or diseases on a calendar schedule, regardless if the pest or problem was observed or not. The "IPM Savvy" group agreed that IPM practices benefited their nursery by saving money $(60 \%)$ and allowing labor to be used more efficiently (61\%). In addition, these respondents were more likely than the other segments to believe IPM practices are beneficial to the environment (93\%) and that there are effective alternatives to chemical pesticides for dealing with most pests (54\%).

The "IPM Savvy" group was more likely to consider obtaining information via technologybased resources, such as e-mail (67\%) and the World Wide Web (62\%), for pest information 
Table 1. Description of three Pennsylvania nursery segments derived from cluster analysis based on participant's responses (in \%) to IPM and cultural practice variables.

\begin{tabular}{|c|c|c|c|c|}
\hline \multirow[b]{2}{*}{ Variable } & \multicolumn{4}{|c|}{ Nursery segment } \\
\hline & IPM Savvy & Part-time IPMer & Reluctant IPMer & Significance $^{2}$ \\
\hline $\mathrm{n}$ & 176 & 96 & 88 & \\
\hline$\%$ & 49 & 27 & 24 & \\
\hline \multicolumn{5}{|l|}{ Frequency with which IPM strategies are used in the nursery: } \\
\hline Routinely & 86 & 68 & 7 & $1,3^{*}$ \\
\hline Sometimes & 14 & 27 & 67 & $1,3^{*}$ \\
\hline Rarely & 0 & 4 & 17 & $1,3^{*}$ \\
\hline \multicolumn{5}{|l|}{ Monitors for insects: } \\
\hline Occasionally & 8 & 9 & 16 & $3^{*}$ \\
\hline \multicolumn{5}{|l|}{ Monitors for weeds: } \\
\hline Annually & 7 & 13 & 2 & $2,3^{*}$ \\
\hline Occasionally & 15 & 21 & 28 & $1,3^{*}$ \\
\hline Once a week during the season & 38 & 26 & 24 & $1^{*}$ \\
\hline \multicolumn{5}{|l|}{ Upon notification of a pest problem by the Pennsylvania } \\
\hline Dept. of Agriculture inspectors & 4 & 13 & 3 & $2^{*}$ \\
\hline \multicolumn{5}{|l|}{ Identifies disease problems accurately: } \\
\hline Always & 42 & 31 & 5 & $1,3^{*}$ \\
\hline Sometimes & 56 & 68 & 86 & $1,3^{*}$ \\
\hline \multicolumn{5}{|l|}{ Identifies insect or mite problems accurately: } \\
\hline Always & 70 & 51 & 24 & $1,3^{*}$ \\
\hline Sometimes & 30 & 49 & 74 & $1,3^{*}$ \\
\hline \multicolumn{5}{|l|}{ Identifies weed problems accurately: } \\
\hline Always & 55 & 50 & 18 & $1,3^{*}$ \\
\hline Sometimes & 42 & 46 & 72 & $1,3^{*}$ \\
\hline \multicolumn{5}{|l|}{ Techniques used to monitor for insects or mites: } \\
\hline Visual inspection & 30 & 27 & 45 & $3^{*}$ \\
\hline Combination of the above & 68 & 73 & 55 & $3^{*}$ \\
\hline Keeps permanent records of pest monitoring & 28 & 32 & 12 & $3^{*}$ \\
\hline \multicolumn{5}{|l|}{ When monitoring for insects or mites: } \\
\hline Identifies the specific insect or mite & 88 & 87 & 73 & $3^{*}$ \\
\hline Identifies the presence of beneficial insects, mites, and other organisms & 42 & 25 & 23 & $1,3^{*}$ \\
\hline Relates insect or mite presence to current and forecasted environmental condition & 40 & 52 & 23 & $2,3^{*}$ \\
\hline Relates insect or mite presence to condition of host plant & 63 & 66 & 39 & $1,3^{*}$ \\
\hline Counts the number of specific insects or mites & 23 & 21 & 10 & $3^{*}$ \\
\hline Considers the following when deciding to treat for insects or mites: & & & & \\
\hline Incidence (how many plants are affected) & 89 & 75 & 76 & $1,2^{*}$ \\
\hline Time of year & 60 & 67 & 40 & $2,3^{*}$ \\
\hline $\begin{array}{l}\text { Phenological indicators (for example, growing degree days, leaf flush, } \\
\text { or flowering of nearby plants) }\end{array}$ & 30 & 38 & 14 & $2,3^{*}$ \\
\hline Uses preventative blanket sprays to treat for insects or mites & 34 & 57 & 35 & $1,2^{*}$ \\
\hline When monitoring for plant diseases: & & & & \\
\hline Identifies the specific disease & 83 & 83 & 58 & $1,3^{*}$ \\
\hline Relates disease presence to current and forecasted environmental conditions & 53 & 49 & 26 & $1,3^{*}$ \\
\hline Determines disease severity & 85 & 81 & 63 & $1,3^{*}$ \\
\hline Considers plant condition & 78 & 73 & 56 & $1,3^{*}$ \\
\hline Considers plant variety & 69 & 71 & 45 & $1,3^{*}$ \\
\hline Considers the following when deciding to treat for a plant disease: & & & & \\
\hline Time of year & 65 & 69 & 47 & $3^{*}$ \\
\hline $\begin{array}{l}\text { Phenological indicators (for example, growing degree days, leaf flush, } \\
\text { or flowering of nearby plants) }\end{array}$ & 28 & 40 & 18 & $2,3^{*}$ \\
\hline Preventative blanket sprays & 39 & 58 & 32 & $2,3^{*}$ \\
\hline Currently uses the following often: & & & & \\
\hline Nursery layout based on key pest and plants to reduce pest access & & & & \\
\hline to susceptible plants & 35 & 44 & 15 & $2,3^{*}$ \\
\hline Isolates plants with pest problems for treatment & 57 & 57 & 41 & $3^{*}$ \\
\hline Weeding maintenance programs & 87 & 84 & 72 & $1,2,3^{*}$ \\
\hline Currently uses the following often: & & & & \\
\hline Monitors for pests & 95 & 90 & 78 & $1,3^{*}$ \\
\hline Selects pesticides that conserve beneficials & 66 & 56 & 41 & $1,3^{*}$ \\
\hline Uses cultural practices that conserve beneficials & 68 & 44 & 38 & $1,2,3^{*}$ \\
\hline Uses cultural practices that reduce weeds & 82 & 75 & 70 & $1 *$ \\
\hline In the future, would like to do more of the following: & & & & \\
\hline Monitors for pests & 27 & 49 & 33 & $1,2^{*}$ \\
\hline Uses cultural practices that reduce weeds & 35 & 58 & 34 & $1,2^{*}$ \\
\hline Currently uses the following often: & & & & \\
\hline Insecticidal soap & 37 & 25 & 28 & $1^{*}$ \\
\hline Horticultural oils & 42 & 36 & 21 & $1^{*}$ \\
\hline Natural products (for example, botanicals) & 29 & 17 & 20 & $1^{*}$ \\
\hline Chemical pesticides & 53 & 87 & 48 & $1,2^{*}$ \\
\hline In the future, would like to do more of the following: & & & & \\
\hline Horticultural oils & 26 & 27 & 17 & $3^{*}$ \\
\hline Chemical pesticides & 7 & 12 & 4 & $3^{*}$ \\
\hline
\end{tabular}




\begin{tabular}{|c|c|c|c|c|}
\hline \multirow[b]{2}{*}{ Variable } & \multicolumn{4}{|c|}{ Nursery segment } \\
\hline & IPM Savvy & Part-time IPMer & Reluctant IPMer & Significance $^{\mathrm{z}}$ \\
\hline \multicolumn{5}{|l|}{ Currently uses the following often: } \\
\hline Identifies weeds & 70 & 72 & 54 & $3^{*}$ \\
\hline Evaluates weed severity & 86 & 87 & 68 & $3^{*}$ \\
\hline Targets persistent problem weeds & 85 & 77 & 62 & $1,3^{*}$ \\
\hline Targets weed control based on vulnerable point within life cycle & 61 & 53 & 32 & $1,3^{*}$ \\
\hline Evaluates weed source (non-crop areas or proper edge) & 48 & 40 & 26 & $1,3^{*}$ \\
\hline Uses preemergence herbicides to reduce overall weed pressure & 45 & 76 & 42 & $1,2,3^{*}$ \\
\hline Uses targeted direct spray herbicides or wipe-on applicators & 56 & 75 & 48 & $2,3^{*}$ \\
\hline Eradicates perennial weeds before replanting a field & 46 & 63 & 26 & $2,3^{*}$ \\
\hline \multicolumn{5}{|l|}{ In the future, would like to do more of the following: } \\
\hline Identifies weeds & 17 & 34 & 27 & $1,2^{*}$ \\
\hline Targets persistent problem weeds & 25 & 37 & 24 & $2^{*}$ \\
\hline Uses preemergence herbicides to reduce overall weed pressure & 29 & 42 & 26 & $2^{*}$ \\
\hline Uses targeted direct spray herbicides or wipe-on applicators & 20 & 35 & 25 & $1,2^{*}$ \\
\hline \multicolumn{5}{|l|}{ Information used in the decision to treat for weed problems: } \\
\hline Incidence of a weed (a weed is present) & 69 & 78 & 64 & $2^{*}$ \\
\hline Species of weed found & 56 & 68 & 44 & $2,3^{*}$ \\
\hline Time of year & 62 & 80 & 65 & $2^{*}$ \\
\hline \multicolumn{5}{|l|}{ Sprays for insects or mites on a set schedule, whether pest is seen or not: } \\
\hline Always & 0 & 15 & 1 & $1^{*}$ \\
\hline Often & 2 & 36 & 3 & $1,2,3^{*}$ \\
\hline Sometimes & 20 & 41 & 33 & $1,2^{*}$ \\
\hline Rarely & 78 & 8 & 63 & $1,2^{*}$ \\
\hline \multicolumn{5}{|l|}{ Sprays for disease on a set schedule, whether a problem is seen or not: } \\
\hline Always & 0 & 19 & 1 & $1,2,3^{*}$ \\
\hline Often & 2 & 41 & 7 & $1,2,3^{*}$ \\
\hline Sometimes & 23 & 38 & 30 & $1,2^{*}$ \\
\hline Rarely & 75 & 2 & 62 & $1,2^{*}$ \\
\hline \multicolumn{5}{|l|}{ Uses herbicides on a set schedule: } \\
\hline Always & 9 & 36 & 0 & $1,2,3^{*}$ \\
\hline Often & 11 & 44 & 7 & $1,2,3^{*}$ \\
\hline Rarely & 60 & 4 & 69 & $1,2,3^{*}$ \\
\hline \multicolumn{5}{|l|}{ The following are a limitation when using IPM: } \\
\hline Sufficient information about pest biology & 57 & 69 & 87 & $1,3^{*}$ \\
\hline Availability of alternatives to chemical pesticides & 72 & 85 & 83 & $1^{*}$ \\
\hline Effectiveness of cultural practices & 67 & 81 & 85 & $1,3^{*}$ \\
\hline Cost of using IPM & 52 & 69 & 73 & $1,3^{*}$ \\
\hline Customer response to IPM & 31 & 42 & 43 & $1^{*}$ \\
\hline Uncertainties about effectiveness of IPM practices & 60 & 84 & 78 & $1,2^{*}$ \\
\hline Time requirements & 68 & 87 & 84 & $1,2^{*}$ \\
\hline Plant pest regulations & 59 & 73 & 87 & $1,3^{*}$ \\
\hline Availability of damage threshold used for making pest management decisions & 63 & 77 & 88 & $1,3^{*}$ \\
\hline \multicolumn{5}{|l|}{ Agree with the following in regards to using IPM practices: } \\
\hline IPM practices would save the nursery money & 60 & 46 & 33 & $1,3^{*}$ \\
\hline IPM practices are beneficial to the environment & 93 & 86 & 78 & $1,3^{*}$ \\
\hline IPM practices allow labor to be used more efficiently at the nursery & 61 & 43 & 27 & $1,3^{*}$ \\
\hline There are alternatives to chemical pesticides that are as & & & & \\
\hline effective in dealing with most pests & 54 & 33 & 41 & $1,2^{*}$ \\
\hline Monitoring pest and reducing pesticide use is too costly to implement & 7 & 20 & 19 & $1,2^{*}$ \\
\hline Would be interested in IPM handout materials to help educate customers & 62 & 67 & 49 & $3^{*}$ \\
\hline Received a higher education degree (associate degree or higher) & 71 & 60 & 58 & $1^{*}$ \\
\hline Participant makes the pest management decisions for the nursery & 99 & 100 & 96 & $3^{*}$ \\
\hline Two or more employees were full time in 1998 & 60 & 70 & 48 & $2,3^{*}$ \\
\hline Three of more employees were seasonal in 1998 & 55 & 70 & 39 & $2,3^{*}$ \\
\hline
\end{tabular}

$\mathrm{z}_{1}=$ Part-time IPMers and Reluctant IPMers combined and tested against 1; $2=$ IPM Savvy and Reluctant IPMers combined and tested against 2; $3=$ IPM Savvy and Part-time IPMers combined and tested against 3; 1,2,3 = all cluster comparisons are significantly different.

Ns, "Nonsignificant or significant at $P=0.05$, as based on a two-tailed $t$ test and Kruskal-Wallis test.

and had used the web (40\%) more often than the other two segments to obtain information. There was a relationship between this group's use of technology and IPM practices and their education level. A greater percentage of the "IPM Savvy" group (71\%) obtained at least an associates' degree, compared to the other two groups.

Segment 2. The second largest segment of the nursery population accounted for 96 of the survey participants (27\%); and was designated as the "Part-time IPMer" group. This segment used some IPM and cultural practices and indicated that they would like to utilize additional practices more often in the future.
Fifty-two percent of this segment monitored for insects or mites by relating presence of the pest to current and forecasted environmental conditions, and $57 \%$ considered using preventive sprays to treat for these pests. "Part-time IPMers" used phenological indicators when deciding to treat for a plant disease $(40 \%)$; they also considered nursery layout based on key pests and key plants to reduce a pest's access to susceptible plants (44\%). This segment used information such as incidence of weeds $(78 \%)$, species of weeds found $(68 \%)$, and time of year $(80 \%)$ more often than the other two segments when deciding how to treat for weed problems.
Of the three segments, "Part-time IPMers" were the greatest overall users of chemical pesticides $(87 \%)$. They were also the greatest users of preemergence herbicides to reduce overall weed pressure $(76 \%)$, thus reducing unplanned and excessive postemergence herbicide use. "Part-time IPMers" were the most likely to always spray herbicides on a set schedule (36\%) and to do the same for insects/mites $(15 \%)$ and diseases $(19 \%)$ whether a pest or problem was seen or not.

Even with this high percentage of chemical usage, the "Part-time IPMers" had the greatest interest among the segments in employing IPM practices more often in the future. This seg- 
ment would like to monitor for pests $(49 \%)$; use cultural practices that reduce weeds (58\%); identify weeds (34\%); use preemergence herbicides to reduce overall weed pressure $(42 \%)$; and use targeted direct spray herbicides or wipe-on applications $(35 \%)$ in the future.

"Part-time IPMers" had questions and concerns about using IPM practices and were more likely to feel that limitations associated with using IPM practices exist, including uncertainty about the effectiveness of (84\%) and time required to implement IPM practices $(87 \%)$. In addition, they were more likely to believe that implementing a monitoring and pest reduction program is too costly $(20 \%)$.

When acquiring information to assist with IPM, "Part-time IPMers" preferred information distributed through phone calls ( $82 \%$ ); evening meetings (84\%); one-day meetings ( $87 \%$ ); pest walks ( $90 \%)$; and multi-session courses (85\%). They were more likely to seek information from other growers (90\%); crop consultants (44\%); cooperative extension meetings outside PA (68\%); the Penn State insect identification lab (57\%); the Penn State plant disease clinic $(61 \%)$; and salespeople $(62 \%)$ than the other two segments.

Demographic differences for this segment were noticeable when reporting the number of full time and seasonal employees in 1998. Of the three segments, "Part-time IPMers" were more likely to employ two or more full time and three or more seasonal employees while the other two segments employed fewer people.

Segment 3. The third segment, designated as "Reluctant IPMers", included 88 survey participants (24\%) and was the least involved in IPM practices of all three segments. "Reluctant IPMers" were least likely to routinely (7\%) use IPM strategies and most likely to employ IPM sometimes $(67 \%)$. This segment only occasionally monitored for insects $(16 \%)$ and were less likely ( $2 \%$ ) than the other two segments to monitor annually for weeds (7\% and $13 \%$ for "IPM Savvy" and "Part-time IPMers," respectively). Similarly, "Reluctant IPMers" gave positive responses less frequently than the other two segments to questions such as: always identifies disease, insect/mite, or weed problems accurately; keeps permanent records of pest monitoring; follows reliable procedures when monitoring for weeds or diseases or considering when to treat for insects/mites or diseases; and has plans to use IPM tactics more often in the future.

As with the "Part-time IPMer," this segment found limitations when using IPM including lack of sufficient information about pest biology (87\%) and effectiveness of cultural practices ( $85 \%$ ); prohibitive cost of using IPM $(73 \%)$ and plant pest regulations $(87 \%)$; and lack of available damage thresholds for making pest management decisions ( $88 \%$ ). "Reluctant IPMers" also had an interest in several methods of information distribution preferring printed materials and person-to-person contact over electronically delivered resources; however, this segment was less likely to want IPM educational materials to distribute to their customers. "Reluctant IPMers" were less apt to take advantage of diagnostic services through the university.

When analyzing demographic information, "Reluctant IPMers" were less likely to have attained a college degree. Finally, nurseries in this segment employed fewer full time and seasonal employees in 1998 than the other two segments.

Trends among segments. The IPM segments revealed important differences in understanding, implementation, perceived limitations, and future interest in applying IPM strategies between the segments. Segment comparisons also identified similarities among IPM groups.

Few of the respondents employed growing degree days in their monitoring strategy for insects, diseases, or weeds although growing degree days and plant phenology guidelines have been developed for insect pest monitoring in Pennsylvania (Hoover, 2002). This suggests that educational efforts on the use of growing degree days and plant phenology can and should be expanded within Pennsylvania.

Very few respondents reported specifically employing traps, foliage samples, or indicator plants as a technique for monitoring insect or mites, although, greater than half reported using a combination of techniques. Lack of documented use of these monitoring techniques provides an opportunity to develop both demonstrations and educational programs centered around their effectiveness, deployment, maintenance, and interpretation on results based on the target insect.

Among the groups, a large proportion of respondents were less confident in their skills to accurately identify insect, disease, and weed problems based on their choice of "sometimes" rather than "always" when completing the survey. This suggests that continued education on identification skills would benefit respondents in each group and strengthen overall confidence.

Amajority ( $83 \%$ to $88 \%$ ) considered insect or mite damage and weed population $(75 \%)$ severity and nearly all segment respondents (80\% to $90 \%$ ) considered disease incidence and severity prior to treating. By considering severity and incidence prior to treatment suggests that most of the respondents have learned to evaluate the pest evidence prior to action.

Nearly one-third (26\% to $38 \%$ ) of respondents would like to do more with nursery layout based on key plants and pests, isolation of plants with pest problems, and weed management. Segment respondents (24\% to $35 \%$ ) reported a future interest in using insecticidal soaps and natural products for insect or mite control, targeting the vulnerable point in weed life cycle for treatment, evaluate weed sources, and use of preemergence herbicides to reduce weed pressure. The above interest for more information and experience provides direction for future education and demonstration programs for extension personnel in Pennsylvania.

Nearly all $(83 \%$ to $90 \%)$ questioned the effectiveness of alternatives to chemical pesticides as a limitation to IPM, while greater than half (51\% to $60 \%$ ) agreed that using fewer chemical pesticides would lower their nursery's risk of being sued. Less than half (34\% to $46 \%$ ) felt their customers would appreciate the use of IPM practices and less than one-third (18\% to $32 \%$ ) considered natural enemies as a cost effective control option. Reduced pesticide use is a recognized benefit of IPM; however, further evidence on the effectiveness of alternative controls, cost effectiveness of natural enemies, and a clearly defined market benefit to customers must be developed in order to convince a majority of the respondents to adopt IPM strategies completely.

\section{Conclusions}

Three distinct IPM practioner segments can be identified in Pennsylvania. The "IPM Savvy" appear to be proficient and comfortable with the level of monitoring and decision-making criteria they are currently employing. They will most likely continue to incorporate new ideas into their IPM programs to satisfy their customers' needs as well as their own. The "Part-time IPMers" appear to be the segment with the greatest immediate educational potential through face-to-face extension programs, fact sheets, and pocket guides designed around IPM skills training, implementation strategies, and cost-benefit demonstrations. Only a small percentage of the "Reluctant IPMer" segment uses IPM practices or has an interest in increasing future involvement. The "Reluctant IPMer" segment needs more education to convince them to use IPM practices. Focusing programming toward the "Part-time IPMers" may result in new techniques and tools to further educate the "Reluctant IPMer."

As a whole, Pennsylvania growers have a high awareness of IPM practices; however, continued education is warranted to enhance pest monitoring and identification skills, use of beneficials, and recordkeeping. Additional research and education is also needed to demonstrate effectiveness of chemical alternatives, cost effectiveness of IPM practices, and marketing benefits of employing IPM practices in the nursery industry.

\section{Literature Cited}

Pennsylvania Dept. of Agriculture. 2000. List of certified nurseries and nursery dealers and stock locator. Commonwealth of Pennsylvania, Dept. of Agr., Bur. of Plant Ind.

Behe, B., S. Barton, C. Hall, C.D. Safley, and S. Turner. 1999. Consumer preference for geranium flower color, leaf variegation, and price. HortScience 34:740-742.

Delahaut, K.A. and C.F. Koval. 1994. Nursery integrated pest management in Wisconsin. HortTechnology 4:72-75.

Dillman, D.A. 2000. Mail and internet surveys: The tailored design method. 2nd ed. Wiley, New York

Dreistadt, S.H. 1994. Pests of landscape trees and shrubs: An integrated pest management guide. Univ. of California Div of Agr. and Nat. Res. Publ. 3359.

Hardy, J., B.K. Behe, T.J. Page, Jr., and R. Schutzki. 1999. Consumer segmentation based on perceived plant knowledge and gardening involvement. Southern Nursery Assoc. Res. Conf. Proc. 44:509-512.

Higginbotham, J.S. 1993. Pest control: IPM use by nursery growers. Amer. Nurs. 177(12):70-74, 
76-77.

Hollingsworth, R.G., A.H. Hara, and K.T. Sewake. 2000. Pesticide use and grower perceptions of pest problems on ornamental crops in Hawaii. J. Ext. 38(1):1-11.

Hoover, G.A. 2002. Collaborative for integrated pest management. Natl. Arborists Assoc., Tree Care Ind. 13:18-24.

Kelley, K.M., B.K. Behe, J.A. Biernbaum, and K.L. Poff. 2001. Consumer preference for edible-flower color, container size, and price. HortScience 36:801-804.

Lamboy, J.S. 2002. Level of adoption of IPM in
New York greenhouses. New York State IPM Prog. Publ. 417.

Nielsen, D.G. 1990. Landscape integrated pest management. J. Arboricult. 16(10): 253-259.

Raupp, M.J. and C.F. Cornell. 1988. Pest prevention: Treating pests to the IPM treatment. Amer. Nurs. 167(3):59-62, 65-67.

Raupp, M.J. 1985. Monitoring: An essential factor to managing pest of landscape trees and shrubs. J. Arboricult. 11(12):349-355

Reed, D. 1999. Mail dominance. Mktg. Week 22(45):41-45.

Rhoads, A.F. 1985. Integrated pest manage- ment - What's it all about? J. Arboricult. 11(12): 369-372.

Sadof, C.S., M.J. Raupp, and J.A. Davidson. 1987. Survey finds defoliated plants won't sell. Amer. Nurs. 166(15):37-39.

Shetlar, D.J., and P.R. Heller. 1984. Survey of insecticide and miticide usage by 158 nurseries in Pennsylvania. J. Environ. Hort. 2(1)16-20.

Willits, F.K. and M. Shields. 2001. Pennsylvania's green industry: Its nature and contribution to the state's economy. Dept. of Agr. Econ. and Rural Soc., Pennsylvania State Univ., University Park. 